ARTICLE

DOI: $10.1038 /$ s41467-018-07655-3

\title{
Solution-processed intermediate-band solar cells with lead sulfide quantum dots and lead halide perovskites
}

Hiroji Hosokawa (1) 1, Ryo Tamaki², Takuya Sawada1, Akinori Okonogi', Haruyuki Sato', Yuhei Ogomi ${ }^{3}$, Shuzi Hayase (iD ${ }^{3}$, Yoshitaka Okada ${ }^{2}{ }^{2} \&$ Toshihiro Yano ${ }^{1}$

The intermediate-band solar cell (IBSC) with quantum dots and a bulk semiconductor matrix has potential for high power conversion efficiency, exceeding the Shockley-Queisser limit. However, the IBSCs reported to date have been fabricated only by dry process and their efficiencies are limited, because their photo-absorption layers have low particle density of quantum dots, defects due to lattice strain, and low bandgap energy of bulk semiconductors. Here we present solution-processed IBSCs containing photo-absorption layers where lead sulfide quantum dots are densely dispersed in methylammonium lead bromide perovskite matrices with a high bandgap energy of $2.3 \mathrm{eV}$ under undistorted conditions. We confirm that the present IBSCs exhibit two-step photon absorption via intermediate-band at room temperature by inter-subband photocurrent spectroscopy.

\footnotetext{
${ }^{1}$ Material Science Research, R\&D, Kao Corporation, 1334 Minato, Wakayama 640-8580, Japan. ${ }^{2}$ Research Center for Advanced Science and Technology, The University of Tokyo, 4-6-1 Komaba, Meguro-ku, Tokyo 153-8904, Japan. ${ }^{3}$ Graduate School of Life Science and Systems Engineering, Kyushu Institute of Technology, 2-4 Hibikino, Wakamatsu-ku, Kitakyushu, Fukuoka 808-0196, Japan. Correspondence and requests for materials should be addressed to H.H. (email: hosokawa.hiroji@kao.com)
} 
ntermediate-band solar cells (IBSCs) have strong potential for high power conversion efficiency (PCE), exceeding the Shockley-Queisser limit ${ }^{1}$. The IBSC has an intermediate-band (IB) between the valence band (VB) and conduction band (CB), within the bandgap of bulk semiconductor in a photo-absorption layer $^{2-4}$. The IBSC provides two-step photon absorption (TSPA) from the VB to IB and from the IB to $\mathrm{CB}$, in addition to the bulk absorption from the VB to $\mathrm{CB}$. Quantum dots (QDs) incorporated into the bulk matrix have been considered as one of the most promising candidates to realize the IBSCs ${ }^{5-11}$. Presently, such IBSCs have been fabricated only by dry process such as the molecular beam epitaxy (MBE) and metal organic chemical vapor deposition (MOCVD). However, it is generally difficult to improve the PCE in dry-processed IBSCs, because restrictions on the materials that can be used make it difficult to increase in the particle density of QDs and in the bandgap energy $\left(E_{\mathrm{BG}}\right)$ of bulk in the photo-absorption layer of the IBSC ${ }^{3,4,7,9,10}$. Also, the dryprocessed IBSCs contain photo-absorption layers with lattice strain introduced by a large lattice-mismatch between the QDs and the bulk matrix, resulting in a decrease in $\mathrm{PCE}^{3,4,6,7,10}$ due to strained-induced defects. In contrast, a solution process has been proposed as a means to fabricate the IBSC. The colloidal QDs have been proposed to be a promising platform for the IBSC ${ }^{12}$. However, no experimental reports on solution-processed IBSC with QDs have been reported to date. Here, we create IBSCs containing photo-absorption layers where QDs are densely dispersed in a bulk matrix with a high $E_{\mathrm{BG}}$ under undistorted conditions by the solution process. The IBSCs are confirmed to exhibit TSPA via IB at room temperature by inter-subband photocurrent spectroscopy.

\section{Results}

Design and fabrication. Taking into account the solution process, we have selected a perovskite compound ${ }^{13-19}$ as the bulk material and the colloidal $\mathrm{QD}^{20-24}$ as the QD-IB material. Lead $(\mathrm{Pb})$ halide perovskite and lead sulfide $(\mathrm{PbS})$ QDs were chosen from the viewpoint of lattice-matching ${ }^{25-27}$. Based on the theoretical calculation of IBSC with a single IB under no concentration (one sun), the optimized band structure has an $E_{\mathrm{BG}}$ of the bulk of $2.4 \mathrm{eV}$, which is split by the IB into two sub-bandgaps of $1.5 \mathrm{eV}$ and $0.9 \mathrm{eV}^{4}$. The IB corresponds to the $\mathrm{CB}$ of $\mathrm{QDs}^{3,4}$. Taking these energy levels into consideration, we selected methylammonium lead bromide $\left(\mathrm{CH}_{3} \mathrm{NH}_{3} \mathrm{PbBr}_{3}\right)$ perovskite, having $E_{\mathrm{BG}}$ of $2.3 \mathrm{eV}^{14}$, as well as $\mathrm{PbS}$ QDs with the size of $4 \mathrm{~nm}$, having $E_{\mathrm{BG}}$ of $1.0 \mathrm{eV}^{25}$, which gives an energy difference between the $\mathrm{VB}$ maximum of the bulk and IB $\left(E_{\mathrm{VI}}\right)$ of $1.5 \mathrm{eV}$ and energy difference between the IB and CB minimum of the bulk $\left(E_{\mathrm{IC}}\right)$ of $0.8 \mathrm{eV}$ (Fig. 1a). In order to obtain a photo-absorption layer with the QD particle density of not less than $1 \times 10^{12} \mathrm{~cm}^{-2}$ per layer which is the highest density achieved by the MBE method ${ }^{28}$, the PbS QDs of 11 volume\% or more were hybridized with the perovskite matrix (Fig. 1b).

Uniform films of $\mathrm{CH}_{3} \mathrm{NH}_{3} \mathrm{PbBr}_{3}$ perovskite can be prepared by spin-coating from a mixture solvent of $\gamma$-butyrolactone (GBL) and dimethyl sulfoxide (DMSO $)^{14}$. However, the photoabsorption layers where $\mathrm{PbS}$ QDs are dispersed in the perovskite matrix could not be fabricated from the mixture solvent of GBL and DMSO, because PbS QDs had low dispersibility in the mixture solvent. Consequently, in the present study, we use $\mathrm{N}, \mathrm{N}$ dimethylformamide (DMF) solvent, in which iodine-capped $\mathrm{PbS}$ QDs can well disperse ${ }^{23}$. The photo-absorption layers are prepared by spin-coating from DMF dispersions containing iodine-capped $\mathrm{PbS}$ QDs with the size of $4 \mathrm{~nm}$ and perovskite raw materials ( $\left.\mathrm{PbBr}_{2}, \mathrm{CH}_{3} \mathrm{NH}_{3} \mathrm{Br}\right)$ (Methods).
Structural characterization. Figure 2 shows X-ray diffraction (XRD) patterns of the photo-absorption layers on mesoporous $\mathrm{TiO}_{2}\left(\mathrm{mTiO}_{2}\right)$ layers. The hybridization of the PbS QDs with the perovskite did not change the XRD peak positions of the perovskite. No peak due to $\mathrm{PbS}$ at $2 \theta=25$ degree was detected. The XRD results revealed that $\mathrm{CH}_{3} \mathrm{NH}_{3} \mathrm{PbBr}_{3}$ perovskite with undistorted lattice ${ }^{29}$ was the main component of the photo-absorption layers.

Scanning electron microscopy (SEM) observations of the photo-absorption layer surface (Fig. 3) indicate the presence of cubic perovskite crystals with the size of 100 to $200 \mathrm{~nm}$. Although the hybridization of the PbS QDs led to coexistence of the smaller perovskite particles with the size of a few-tens $\mathrm{nm}$, the surface coverage of the perovskite on the substrates (70 to $80 \%$ ) did not depend on the amounts of the PbS QDs.

Based on the cross-sectional SEM image (Fig. 4a), the thickness of the photo-absorption layer with the PbS QDs of 14 volume\% was between $100 \mathrm{~nm}$ to $200 \mathrm{~nm}$. In the magnified SEM image of the photo-absorption layer (Fig. 4b), inside the gray perovskite region, spherical particles (white regions) of 3 to $15 \mathrm{~nm}$ in particle size appear in a scattered manner, indicating how the PbS QDs have been scattered within the perovskite matrix ${ }^{25,26}$. Furthermore, high-resolution transmission electron microscopy (HRTEM) observations (Fig. 4c) show how spherical particles (black regions), with the size of 3 to $15 \mathrm{~nm}$, were densely dispersed, although the larger particles were formed by aggregation of the PbS QDs with the size of $4 \mathrm{~nm}$ by electron beams. In addition, when magnifying and observing the PbS QDs (black regions, Fig. 4d) and the perovskites (gray region, Fig. 4e), lattice fringes matching the interplanar spacing $(0.34 \mathrm{~nm})$ of the $(111)$ plane of cubic $\mathrm{PbS}^{30}$ and the interplanar spacing $(0.30 \mathrm{~nm})$ of the (200) plane of tetragonal $\mathrm{CH}_{3} \mathrm{NH}_{3} \mathrm{PbBr}_{3}{ }^{29}$ are seen, confirming that the $\mathrm{PbS}$ QDs were dispersed in the $\mathrm{CH}_{3} \mathrm{NH}_{3} \mathrm{PbBr}_{3}$ perovskite matrix under the undistorted condition.

Optical properties. No change in the perovskite absorption peak of $530 \mathrm{~nm}$ was observed even after hybridizing the $\mathrm{PbS}$ QDs (Fig. 5), indicating that the perovskite $E_{\mathrm{BG}}$ of $2.3 \mathrm{eV}$ was constant. Near-infrared (NIR) photoluminescence (PL) spectra excited at $785 \mathrm{~nm}$ exhibited emission peaks of the PbS QDs at $1210 \mathrm{~nm}$ (Fig. 5). Although the emission intensity increased with increasing content of the PbS QDs, the peak wavelength remained constant. Thus, the $E_{\mathrm{BG}}$ of $\mathrm{PbS} \mathrm{QDs}$ in the photoabsorption layers was determined to be $1.0 \mathrm{eV}$. It has been reported that $\mathrm{PbS} \mathrm{QDs}$ with $E_{\mathrm{BG}}$ of $1.0 \mathrm{eV}$ have a mean particle diameter of $4 \mathrm{~nm}^{25}$.

Note that NIR emission of the PbS QDs was observed even by exciting the perovskite (excitation wavelength of $532 \mathrm{~nm}$, Supplementary Fig. 1a) in the photo-absorption layers. This result indicates that a part of the charged-carriers photogenerated in the perovskite transfers to the $\mathrm{PbS} \mathrm{QDs}^{25-27}$, due to the fact that the $\mathrm{VB}$ maximum and the $\mathrm{CB}$ minimum of $\mathrm{PbS}$ QDs exist within the bandgap of the perovskite (Fig. 1a). The carrier transfer from the perovskite to $\mathrm{PbS}$ QDs was also supported by experimental results that emission intensity and lifetime of the perovskite decreased with the small amounts of the PbS QDs (Supplementary Fig. 1b, c), while the decrease in the emission intensity and lifetime of the perovskite may be partly attributed from the lower crystallinity of the perovskite (Supplementary Fig. 2).

As the excitation power density increased, the NIR emission intensity linearly increased and the emission peak wavelength blueshifted (Fig. 6, Supplementary Fig. 3), confirming electron coupling between the $\mathrm{PbS}$ QDs, i.e., the IB formation ${ }^{31}$ in the photoabsorption layers with the $\mathrm{PbS} \mathrm{QDs}$ and the perovskite. The emission peak shift was nearly saturated at about $1.058 \mathrm{eV}$ when 
a

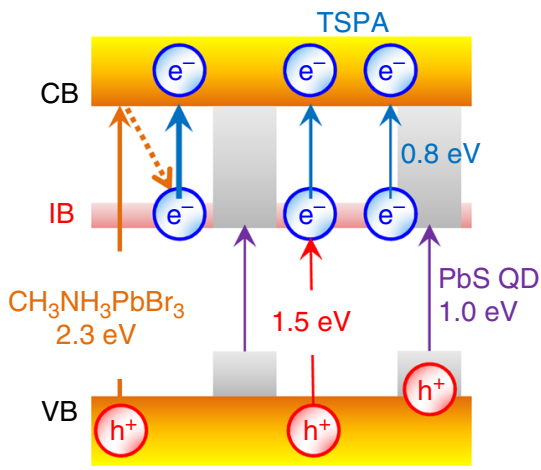

b

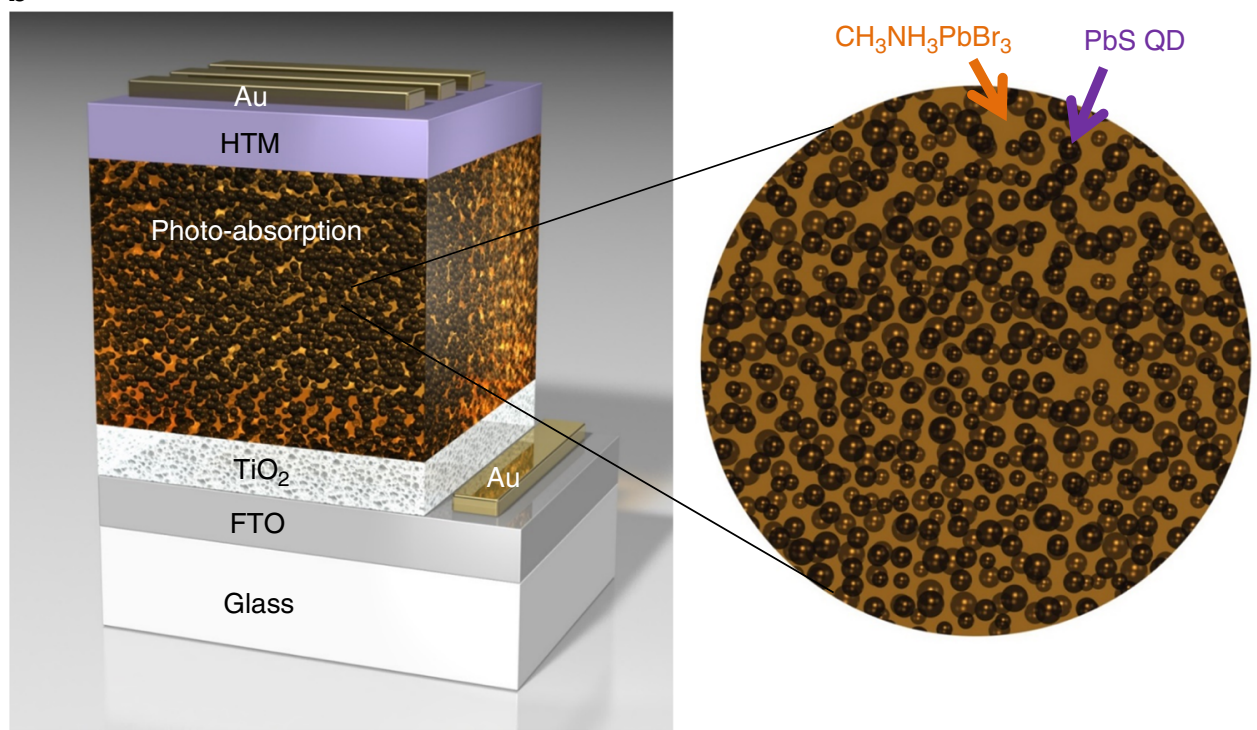

Fig. 1 Design of solution-processed IBSC with $\mathrm{PbS} \mathrm{QDs}$ and $\mathrm{CH}_{3} \mathrm{NH}_{3} \mathrm{PbBr}_{3}$ perovskite. a Schematic energy band diagram of the photo-absorption layer. $E_{\mathrm{BG}}$ of $\mathrm{CH}_{3} \mathrm{NH}_{3} \mathrm{PbBr}_{3}$ perovskite; $2.3 \mathrm{eV}, E_{\mathrm{BG}}$ of $\mathrm{PbS} \mathrm{QD} ; 1.0 \mathrm{eV}, E_{\mathrm{VI}} ; 1.5 \mathrm{eV}, E_{\mathrm{IC}} ; 0.8 \mathrm{eV}$. b Structural model of the IBSC. The photo-absorption layer, where PbS QDs with the mean size of $4 \mathrm{~nm}$ are densely dispersed in the perovskite matrix, is placed between $\mathrm{TiO}_{2}$ and hole-transporting material (HTM)

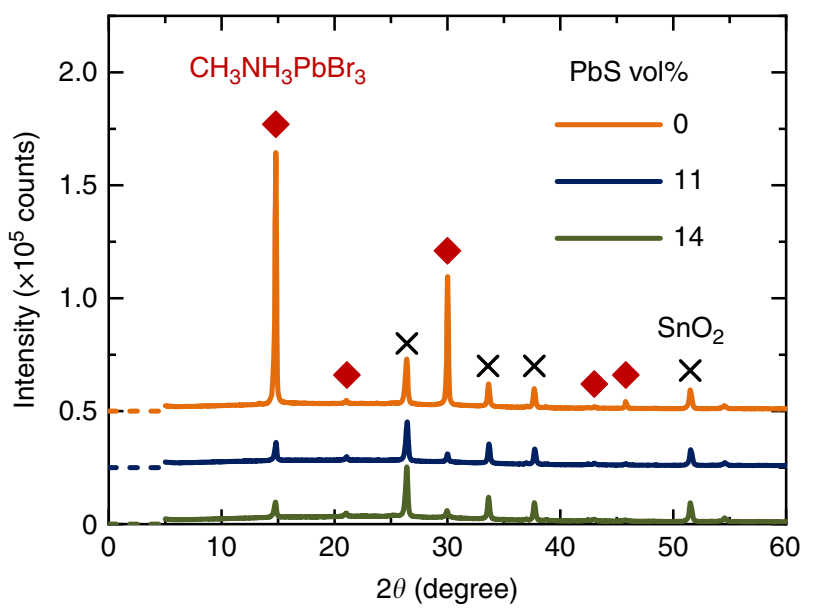

Fig. $2 \times R D$ patterns of the photo-absorption layers. The peaks at $2 \theta=14.8$, 21.1, 30.0, 43.0, 45.8 degree correspond to the (100), (110), (200), (220), (300) reflections of cubic $\mathrm{CH}_{3} \mathrm{NH}_{3} \mathrm{PbBr}_{3}$ perovskite. The peaks at $2 \theta=$ 26.4, 33.6, 37.7, 51.5 degree assign to $\mathrm{SnO}_{2}$ of FTO substrates

excited at the excitation density of $1226 \mathrm{~W} \mathrm{~cm}^{-2}$. The blue-shifted energy was calculated to be $0.02 \mathrm{eV}$, which corresponds to the width of their IB. In summary, the band structure of the photo-absorption layer prepared was identified as designed (Fig. 1a).
Solar cell properties. External quantum efficiency (EQE) values in the visible light region from $400 \mathrm{~nm}$ to $550 \mathrm{~nm}$ (Fig. $7 \mathrm{a}$ ) were decreased by hybridizing the PbS QDs, while EQE values in NIR light region from $600 \mathrm{~nm}$ to $1250 \mathrm{~nm}$ (Fig. 7b) were increased with the PbS QDs. The EQE onset wavelengths $(550 \mathrm{~nm}$ and $1250 \mathrm{~nm})$ were consistent with $E_{\mathrm{BG}}$ of the perovskite $(2.3 \mathrm{eV})$ and the PbS QDs $(1.0 \mathrm{eV})$, respectively. Thus, the EQE values in the visible and NIR light regions are derived from the chargedcarriers photogenerated in the perovskite and the PbS QDs, respectively. Consequently, the decrease of $\mathrm{EQE}$ in the visible region for the cells with $\mathrm{PbS}$ QDs should be explained in terms of the carrier transfer from the perovskite to the $\mathrm{PbS}$ QDs as described above. As a result, PCE values were decreased by hybridizing the PbS QDs (Supplementary Fig. 4). The changes in the solar cell properties by the PbS QDs are similar to those by InAs QDs in dry-processed IBSC. However, the NIR EQE due to the PbS QDs ( 0.1 to $0.2 \%$ at $1000 \mathrm{~nm}$, Fig. $7 \mathrm{~b})$ was much lower than that in the dry-processed IBSC $(6 \% \text { at } 920 \mathrm{~nm})^{8}$, suggesting that thermal excitation from the IB to the perovskite $\mathrm{CB}$ may be suppressed because of the larger $E_{\mathrm{IC}}(0.8 \mathrm{eV})$ in the present IBSCs.

The values of $\triangle \mathrm{EQE}$ using IR bias light with more than 1319 nm (less than $0.94 \mathrm{eV}$ ) increased with the PbS QDs (Fig. 7c, d). In the visible light region (Fig. $7 \mathrm{c}$ ), $\triangle \mathrm{EQE}$ spectra steeply increased at $550 \mathrm{~nm}$ which was consistent with $E_{\mathrm{BG}}$ of the perovskite $(2.3 \mathrm{eV})$. Consequently the $\triangle \mathrm{EQE}$ spectra between $500 \mathrm{~nm}$ and $550 \mathrm{~nm}$ are derived from the photo-excitation of the perovskite. 

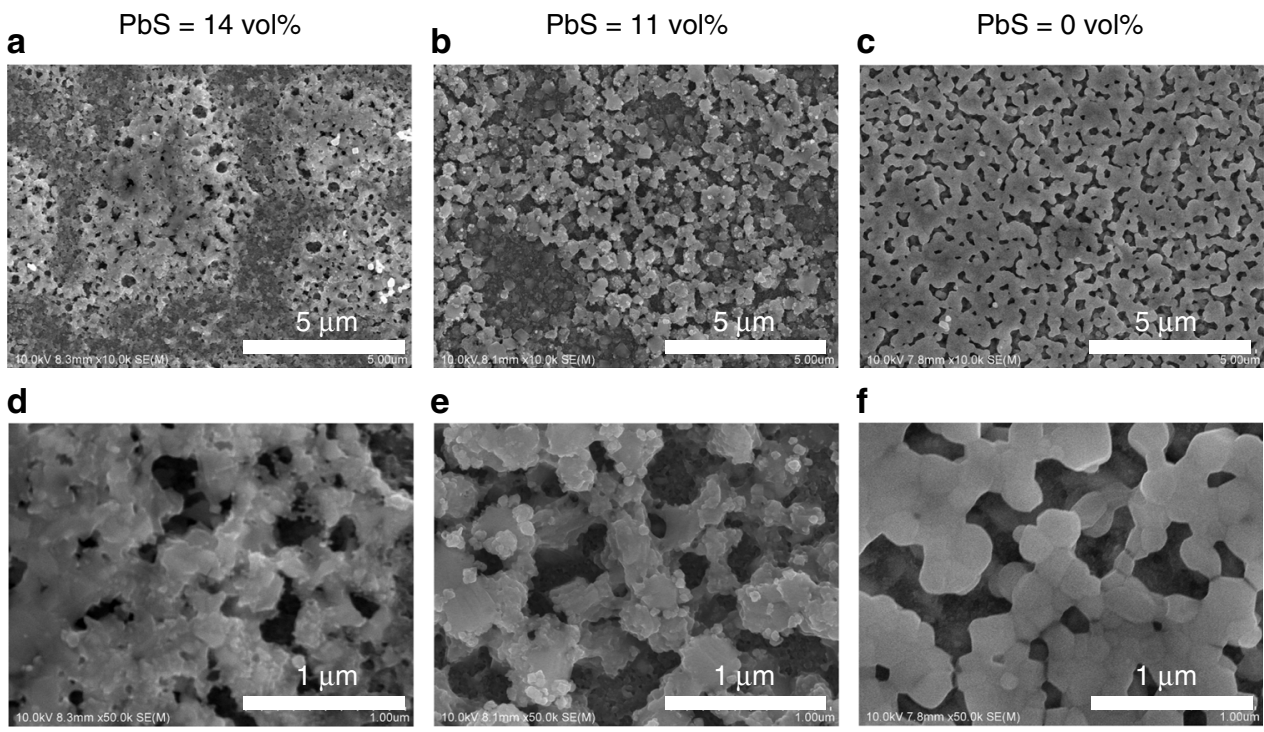

Fig. 3 Top-view SEM images of the photo-absorption layers. The PbS volume concentrations in the photo-absorption layers were 14 volume\% (a, d), 11 volume $\%(\mathbf{b}, \mathbf{e})$, and 0 volume $\%(\mathbf{c}, \mathbf{f})$, respectively
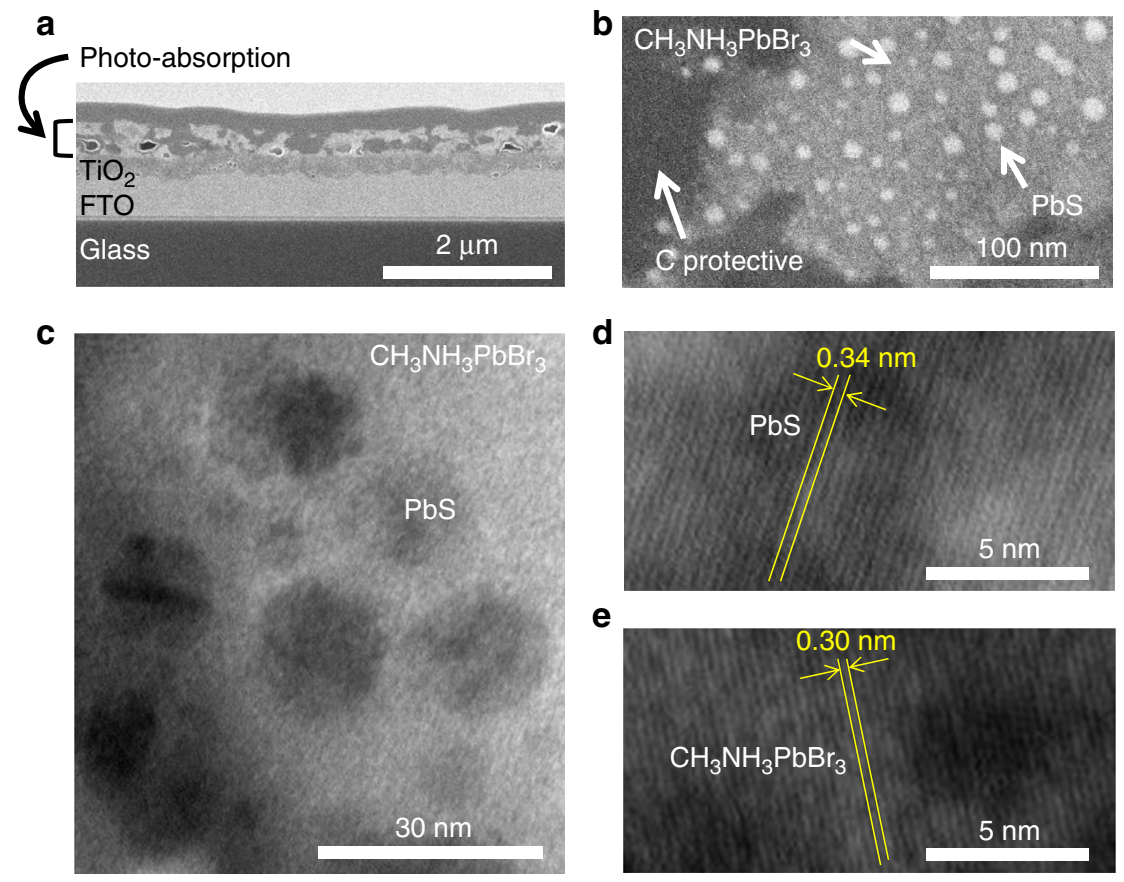

e

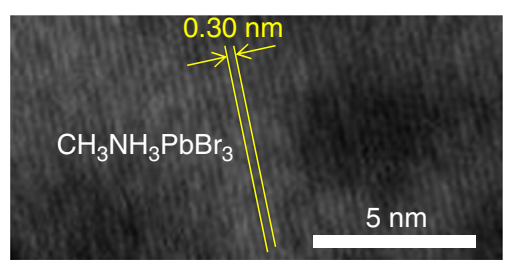

Fig. 4 Cross-sectional SEM and HRTEM images. a Cross-sectional SEM image. From the bottom, glass substrate, $\mathrm{FTO}_{\text {layer, }} \mathrm{TiO}_{2}$ layer, photo-absorption layer, carbon protective layer, tungsten protective layer. $\mathbf{b}$ High-magnification SEM and $\mathbf{c}$ HRTEM images of the photo-absorption layer. $\mathbf{d}$ HRTEM image of the PbS QD (black part). e HRTEM image of the $\mathrm{CH}_{3} \mathrm{NH}_{3} \mathrm{PbBr}_{3}$ perovskite (gray part)

Taking into account the fact that the perovskite cell without the $\mathrm{PbS} \mathrm{QDs}$ has no IB, the $\triangle \mathrm{EQE}$ spectrum of the perovskite cell, which was almost independent on the IR bias light energy (Supplementary Fig. 5, 6) should arise from the photo-excitation of shallow-trapped electrons on defects of the perovskite ${ }^{32}$. In contrast, the $\triangle \mathrm{EQE}$ values of the hybrid cells with the PbS QDs fell by the decrease in IR bias light energy from less than $0.94 \mathrm{eV}$ to less than $0.83 \mathrm{eV}$ (Supplementary Fig. 5, 6), indicating the narrow energy distribution of the IB $(0.02 \mathrm{eV}$, Fig. 6$)$ with the $E_{\mathrm{IC}}$ of $0.8 \mathrm{eV}$ (Fig. 1a). Thus, the $\triangle \mathrm{EQE}$ spectra between $500 \mathrm{~nm}$ and $550 \mathrm{~nm}$ of the hybrid cells with the PbS QDs should be explained in terms of the TSPA of the IB electrons transferred from the perovskite $\mathrm{CB}$, since the carrier transfer from the perovskite to the $\mathrm{PbS} \mathrm{QDs}^{25-27}$ has been supported by the emission behavior (Supplementary Fig. 1) and the cell characteristics (Fig. 7a, Supplementary Fig. 4). In the NIR light region (Fig. 7d), the hybrid cells with the PbS QDs exhibited $\triangle \mathrm{EQE}$ spectra with the onset at around $1250 \mathrm{~nm}$ and the rising at around $850 \mathrm{~nm}$ in contrast to the perovskite cell with $\triangle \mathrm{EQE}=0 \%$. The wavelengths of the onset and the rising were consistent with the $E_{\mathrm{BG}}$ of $\mathrm{PbS}$ QDs $(1.0 \mathrm{eV})$ and the $E_{\mathrm{VI}}(1.5 \mathrm{eV})$, respectively (Fig. 1a). Consequently, the $\triangle \mathrm{EQE}$ spectra between around $850 \mathrm{~nm}$ and around $1250 \mathrm{~nm}$ can be attributed to the TSPA where electrons photo-excited from the PbS QD VB to the IB (PbS QD CB) are 
further photo-excited to the perovskite $\mathrm{CB}$. The $\triangle \mathrm{EQE}$ spectra ranging from $600 \mathrm{~nm}$ to around $850 \mathrm{~nm}$ should be partly due to the TSPA of the IB electrons photo-excited from the perovskite VB. Thus, the hybrid cells with the PbS QDs exhibited the TSPA via the IB, confirming that they were functioning as the IBSCs at room temperature.

\section{Discussion}

We prepared the photo-absorption layers by the solution process of spin-coating from the DMF dispersions containing the $\mathrm{PbS}$ QDs with the size of $4 \mathrm{~nm}$ and the perovskite raw materials $\left(\mathrm{PbBr}_{2}, \mathrm{CH}_{3} \mathrm{NH}_{3} \mathrm{Br}\right)$. The structural and spectroscopic characterizations of the photo-absorption layers indicated that the $\mathrm{PbS}$ QDs with the $E_{\mathrm{BG}}$ of $1.0 \mathrm{eV}$ were densely dispersed in $\mathrm{CH}_{3} \mathrm{NH}_{3} \mathrm{PbBr}_{3}$ perovskite matrices with the $E_{\mathrm{BG}}$ of $2.3 \mathrm{eV}$ under undistorted conditions as designed in Fig. 1. The blue-shift in NIR PL with increasing excitation density (Fig. 6b) confirmed IB formation in the photo-absorption layers. The cells with the photo-absorption layers exhibited the TSPA via the IB at room temperature by the inter-subband photocurrent spectroscopy as shown in Fig. 7c, d. Thus, we can conclude that a solution process was a powerful tool to fabricate IBSCs without limitations often reported for dry-processed IBSCs.

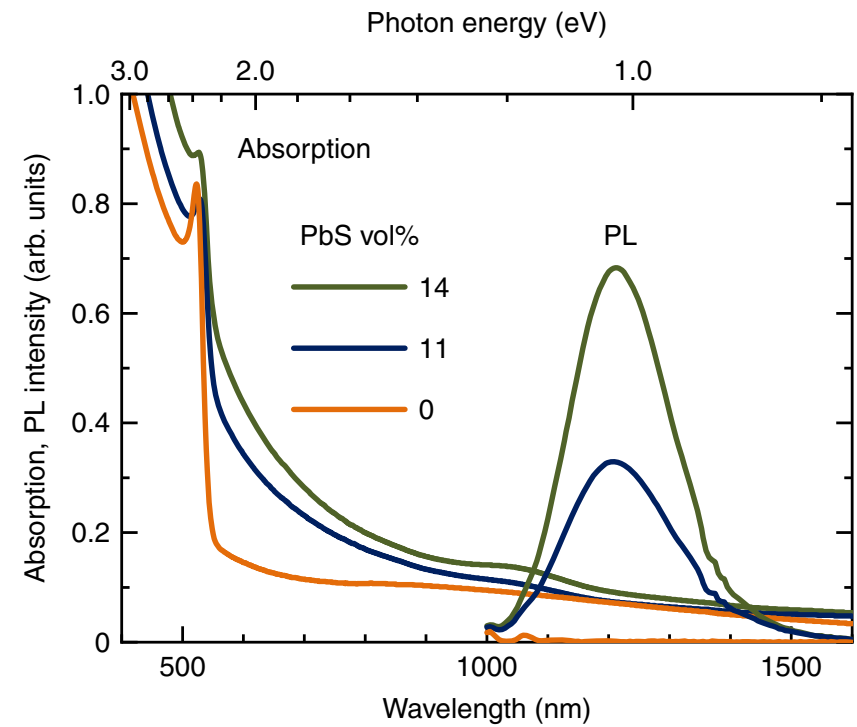

Fig. 5 Absorption and NIR PL spectra of the photo-absorption layers at room temperature. Excitation wavelength was $785 \mathrm{~nm}$

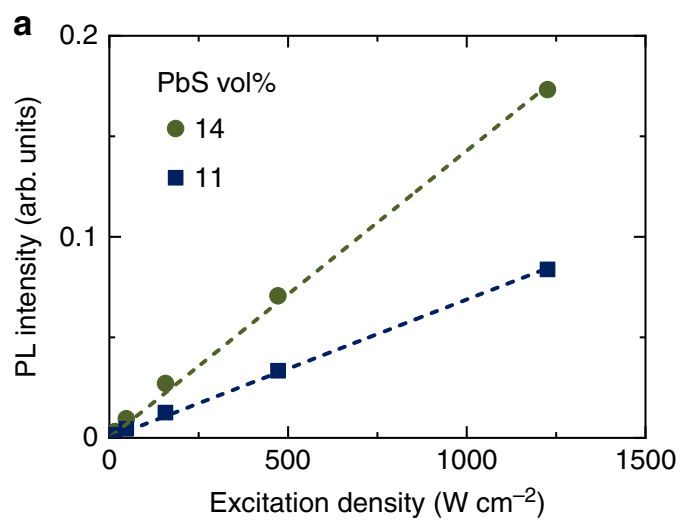

As shown in Supplementary Fig. 4, the PCE values of the present IBSCs with the PbS QDs and the perovskite were low because of some factors such as the carrier transfer from the perovskite to the $\mathrm{PbS}$ QDs and poor film quality. However, an incorporation of a tunneling barrier with $\mathrm{CB}$ minimum above that of the perovskite into the interface between the PbS QDs and the perovskite may block the carrier transfer from the perovskite to the $\mathrm{PbS} \mathrm{QDs}$, leading to hign $\mathrm{PCE}^{33}$. And also, the carrier transfer may be suppressed by control of their energy levels like type-II structure ${ }^{4}$ which can be realized by hybridizing a QD material with VB maximum below that of the perovskite. In addition, the TSPA process should be enhanced by increasing the lifetime of carriers in the intermediate state with photon ratchet ${ }^{34}$ and in type-II structure ${ }^{4}$. Further investigations are currently underway to enhance the solar cell performance by suppressing the carrier transfer and by improving the film quality. The present results pave the way towards not only high PCE but also low cost, flexible IBSCs.

\section{Methods}

Synthesis of PbS quantum dots (QDs). Oleate-capped $\mathrm{PbS}$ quantum dots (QDs) were synthesized according to a previously published method ${ }^{35}$. A mixture of 0.45 $\mathrm{g}$ of lead oxide (99.999\%), $10 \mathrm{~g}$ of 1-octadecene (ODE, more than 95\%), and $1.34 \mathrm{~g}$ of oleic acid (more than $90 \%$ ) was degassed at $353 \mathrm{~K}$ for $2 \mathrm{~h}$. The obtained solution was heated to $383 \mathrm{~K}$ and kept for $30 \mathrm{~min}$ under $\mathrm{N}_{2}$, followed by rapid injection of an ODE solution $(4 \mathrm{~mL})$ of 1,1,1,3,3,3-hexamethyldisilathiane $(0.21 \mathrm{~mL})$. After injection, the obtained colloidal solution was allowed to cool down to room temperature, and $\mathrm{PbS}$ QD solid was separated by adding acetone and centrifugation. The oleate-capped PbS QDs were characterized by inductively coupled plasma (ICP) analysis, X-ray photoelectron spectroscopy (XPS), proton nuclear magnetic resonance $\left({ }^{1} \mathrm{H}\right.$ NMR) spectroscopy, X-ray diffraction (XRD), absorption and photoluminescence (PL) spectroscopies, as described below. The weight concentrations of $\mathrm{Pb}$ and oleic acid in the oleate-capped $\mathrm{PbS} \mathrm{QD}$ solid were measured to be $55 \mathrm{wt} \%$ and $28 \mathrm{wt} \%$ by ICP analysis and ${ }^{1} \mathrm{H}$ NMR spectroscopy, respectively. The molar ratio of oleate to $\mathrm{Pb}$ (oleate/ $\mathrm{Pb}$ ) could be calculated to be 0.37 . The atomic ratio of $\mathrm{Pb} / \mathrm{S} / \mathrm{I} / \mathrm{N}$ was determined to be $1 / 0.58 / 0 / 0$ by using XPS. The crystalline size of the oleate-capped PbS QDs was measured to be $3.0 \mathrm{~nm}$ by XRD. The bandgap energy $\left(E_{\mathrm{BG}}\right)$ of the oleate-capped $\mathrm{PbS}$ QDs was estimated to be $1.2 \mathrm{eV}$ from absorption onset wavelength $(1050 \mathrm{~nm})$ and emission peak wavelength $(1040 \mathrm{~nm})$ excited at $800 \mathrm{~nm}$.

The above oleate-capped PbS QD solid could be dispersed in toluene, but not in $N, N$-dimethylformamide (DMF), which was a good solvent for a solution of perovskite raw materials $\left(\mathrm{PbBr}_{2}, \mathrm{CH}_{3} \mathrm{NH}_{3} \mathrm{Br}\right)$. Consequently iodine (I)-capped $\mathrm{PbS}$ QDs with high dispersibility in DMF were synthesized by ligand exchange process $^{23}$ at room temperature. In the ligand exchange process, DMF-solvated Iligands replace oleate ligands on the $\mathrm{PbS} \mathrm{QD}$ surface. In a glovebox, $0.20 \mathrm{~g}$ of the above oleate-capped PbS QD solid was dispersed in $2 \mathrm{~mL}$ of toluene (super dehydrated). A mixed solution of $1 \mathrm{~mL}$ of toluene, $0.5 \mathrm{~mL}$ of DMF (super dehydrated), and $0.062 \mathrm{~g}$ of $\mathrm{CH}_{3} \mathrm{NH}_{3} \mathrm{I}$ (MAI) was dropwise added to the $\mathrm{PbS}$ dispersion for $11 \mathrm{~min}$ without stirring. The molar ratio of MAI to oleate of $\mathrm{PbS}$ QDs (MAI/oleate) could be calculated to be 2 . After $18 \mathrm{~h}, 5 \mathrm{~mL}$ of methanol (super dehydrated) was added to the $\mathrm{PbS}$ dispersion in order to precipitate I-capped $\mathrm{PbS}$ QD solid. The I-capped PbS QD solid was separated by filtration using polytetrafluoroethylene (PTFE) filters with the pore size of $0.20 \mu \mathrm{m}$. The weight

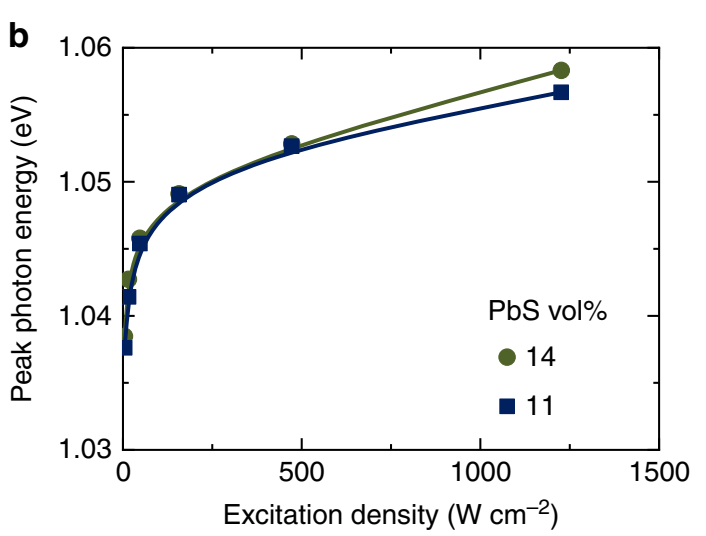

Fig. 6 Excitation density dependence of NIR PL of the photo-absorption layers. a Emission intensity and $\mathbf{b}$ emission peak energy at room temperature. Excitation wavelength was $532 \mathrm{~nm}$ 
a

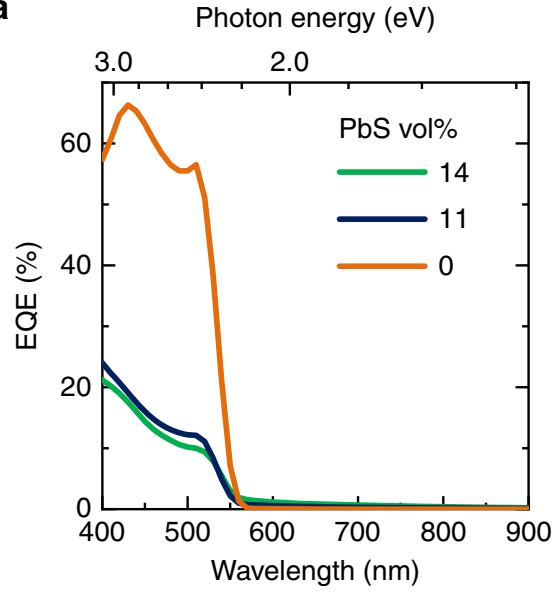

C

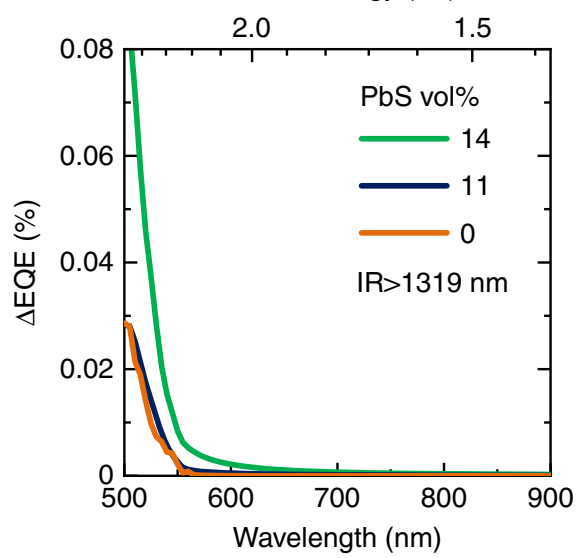

b

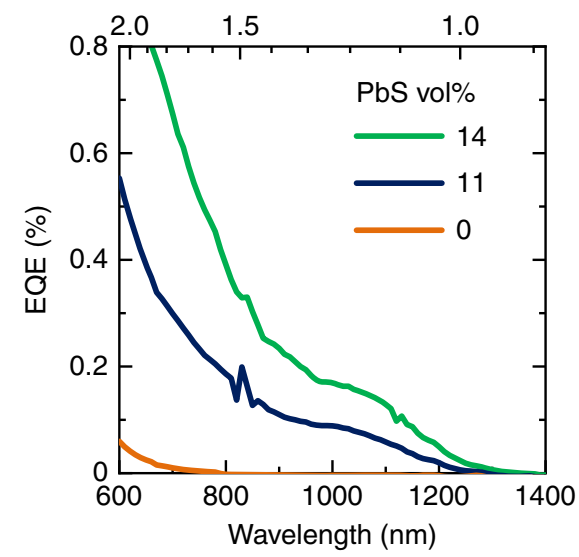

d

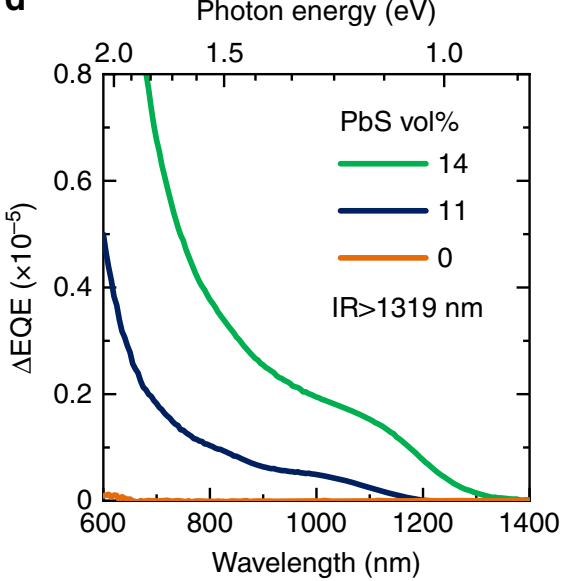

Fig. 7 Spectral response of solution-processed IBSCs with $\mathrm{PbS} \mathrm{QDs}$ and $\mathrm{CH}_{3} \mathrm{NH}_{3} \mathrm{PbBr}_{3}$ perovskite. a $\mathrm{EQE}$, b magnified $\mathrm{EQE}$, $\mathbf{c} \Delta \mathrm{EQE}$, and $\mathbf{d}$ magnified $\Delta \mathrm{EQE}$ spectra at room temperature. The wavelength of IR bias light was more than $1319 \mathrm{~nm}$

concentrations of $\mathrm{Pb}$ and oleic acid in the I-capped $\mathrm{PbS} \mathrm{QD}$ solid were measured to be $55 \mathrm{wt} \%$ and $1 \mathrm{wt} \%$ by ICP analysis and ${ }^{1} \mathrm{H}$ NMR spectroscopy, respectively. The molar ratio of oleate to $\mathrm{Pb}$ (oleate/ $\mathrm{Pb}$ ) could be calculated to be 0.01 . The atomic ratio of $\mathrm{Pb} / \mathrm{S} / \mathrm{I} / \mathrm{N}$ was determined to be $1 / 0.51 / 0.49 / 0$ by using XPS. The crystalline size of the I-capped PbS QDs was measured to be $3.5 \mathrm{~nm}$ by XRD. The $E_{\mathrm{BG}}$ of the Icapped $\mathrm{PbS}$ QDs was determined to be $1.0 \mathrm{eV}$ from absorption onset wavelength $(1200 \mathrm{~nm})$.

Solar cell fabrication. A compact blocking $\mathrm{TiO}_{2}\left(\mathrm{cTiO}_{2}\right)$ layer with the thickness of less than $30 \mathrm{~nm}$ was deposited on a UV-ozone-cleaned fluorine-doped tin oxide (FTO)-coated glass substrate (Asahi Glass Co., Ltd., $25 \times 25 \times 1.8 \mathrm{~mm}$ ) by spray pyrolysis at $723 \mathrm{~K}$ from a precursor solution of $4.04 \mathrm{~g}$ bis(isopropoxide)bis(acetylacetonato)-titanium(IV) (75 wt\% in 2-propanol) in $123.24 \mathrm{~g}$ ethanol (super dehydrated). The $\mathrm{cTiO}_{2}$ layer was treated with $0.05 \mathrm{~mol} \mathrm{~L}^{-1}$ aqueous solution of $\mathrm{TiCl}_{4}$ at $343 \mathrm{~K}$ for $30 \mathrm{~min}$ and rinsed with water. The $\mathrm{cTiO}_{2}$ substrate was sintered at $773 \mathrm{~K}$ for $20 \mathrm{~min}$. A mesoporous $\mathrm{TiO}_{2}\left(\mathrm{mTiO}_{2}\right)$ layer with the thickness of about $200 \mathrm{~nm}$ was coated on the $\mathrm{CTiO}_{2}$ substrate by spin-coating with a speed of 5000 $\mathrm{rpm}$ for $30 \mathrm{~s}$ from a diluted solution of $20 \mathrm{~nm} \mathrm{TiO} \mathrm{T}_{2}$ particle paste (PST-18NR, JGC Catalysts and Chemicals Ltd.) with the weight ratio of $\mathrm{TiO}_{2}$ paste: ethanol of 1:3.5, and then the substrate was sintered at $773 \mathrm{~K}$ for $30 \mathrm{~min}$.

As described above, we used DMF solvent for the perovskite precursor $\left(\mathrm{PbBr}_{2}\right.$, $\mathrm{CH}_{3} \mathrm{NH}_{3} \mathrm{Br}$ ), because the above I-capped PbS QDs could well disperse in DMF ${ }^{23}$. In the preliminary experiment in DMF solvent, we performed the precursor concentration $\left(0.15\right.$ to $\left.1.0 \mathrm{~mol} \mathrm{~L}^{-1}\right)$ studies on the solar cell properties of the perovskite cells without PbS QDs though not shown here. From the viewpoint of their solar cell properties, the precursor concentration in DMF was selected to be $0.31 \mathrm{~mol} \mathrm{~L}^{-1}$. In the glovebox, the above I-capped PbS QD solids $(0$ to $0.20 \mathrm{~g})$ were mixed with $0.31 \mathrm{~mol} \mathrm{~L}^{-1}$ solutions $(2 \mathrm{~mL})$ of $\mathrm{PbBr}_{2}$ (perovskite precursor grade) and $\mathrm{CH}_{3} \mathrm{NH}_{3} \mathrm{Br}$ in DMF (super dehydrated) with stirring at room temperature for $15 \mathrm{~min}$, and then the resulting solutions were filtered with PTFE filters with the pore size of $0.45 \mu \mathrm{m}$. The $\mathrm{PbS}$ weight concentrations $\left(\mathrm{mg} \mathrm{mL}^{-1}\right)$ in the filtrates were determined from absorbance $(A)$ at the peak wavelength $(960$ to $1100 \mathrm{~nm})$ after appropriate dilution by DMF $\left(\mathrm{PbS}=1.2 \mathrm{mg} \mathrm{mL}^{-1} \mathrm{~A}^{-1}\right)$. The PbS volume concentrations in the photo-absorption layers (volume $\%=($ volume of $\mathrm{PbS}) /$ $\left\{(\right.$ volume of $\mathrm{PbS})+\left(\right.$ volume of $\left.\left.\left.\mathrm{CH}_{3} \mathrm{NH}_{3} \mathrm{PbBr}_{3}\right)\right\} \times 100\right)$ were calculated on the basis of the density of $7.5 \mathrm{~g} \mathrm{~cm}^{-3}$ for PbS and that of $3.8 \mathrm{~g} \mathrm{~cm}^{-3}$ for $\mathrm{CH}_{3} \mathrm{NH}_{3} \mathrm{PbBr}_{3}{ }^{36}$. The photo-absorption layer was deposited on the $\mathrm{mTiO}_{2}$ substrate by spin-coating with speeds of $500 \mathrm{rpm}$ for $5 \mathrm{~s}, 1000 \mathrm{rpm}$ for $40 \mathrm{~s}$, and $3000 \mathrm{rpm}$ for $50 \mathrm{~s}$ with the respective slopes of $5 \mathrm{~s}$ from the filtrates. One milliliter toluene (super dehydrated) as a poor solvent was dripped onto the substrate center at $20 \mathrm{~s}$ after the beginning of the spin-coating. After that, the photo-absorption layer on the $\mathrm{mTiO}_{2}$ substrate was dried on a hot plate at $373 \mathrm{~K}$ for $10 \mathrm{~min}$. At the same time, the photo-absorption layer was similarly fabricated on a glass substrate (Matsunami Glass Ind., Ltd., $26 \times 25 \times 1.0 \mathrm{~mm}$ ) as described above for measurement of their optical properties. We verified that the photo-absorption layer on the glass substrate was almost equivalent to that on the $\mathrm{mTiO}_{2}$ substrate by means of XRD, absorption spectroscopy, and SEM observation.

The hole-transporting material (HTM) layer was deposited on the photoabsorption layer by spin-coating with a speed of $4000 \mathrm{rpm}$ for $30 \mathrm{~s}$ from a 0.058 mol L ${ }^{-1}$ solution of $\left(2,2^{\prime}, 7,7^{\prime}\right.$-tetrakis( $N, N$-di-p-methoxyphenylamine)-9,9spirobifluorene) (Spiro-OMeTAD) in chlorobenzene containing 4-tertbutylpyridine $\left(0.19 \mathrm{~mol} \mathrm{~L}^{-1}\right)$, lithium bis-(trifluoromethylsulfonyl)imide $(0.031$ $\left.\mathrm{mol} \mathrm{L}^{-1}\right)$, and tris(2-(1H-pyrazol-1-yl)-4-tert-butylpyridine) cobalt(III) $(5.6 \mathrm{mmol}$ $\mathrm{L}^{-1}$ ). The resulting film was dried on a hot plate at $343 \mathrm{~K}$ for $30 \mathrm{~min}$.

Finally, $100 \mathrm{~nm}$ of gold was thermally evaporated with the deposition rate of 0.8 to $0.9 \mathrm{~nm} \mathrm{~s}^{-1}$ on top of the HTM layer under high vacuum $\left(4\right.$ to $\left.5 \times 10^{-3} \mathrm{~Pa}\right)$.

Structural characterization. XRD patterns were recorded on a X-ray diffractometer (Rigaku, Mini Flex600, light source $\mathrm{CuK} \alpha$, tube voltage $40 \mathrm{kV}$, tube current $15 \mathrm{~mA}$ ) under the conditions of sampling width of 0.02 degree, scan speed of 20 degree $\mathrm{min}^{-1}$, solar slit of 5.0 degree, divergence slit of $13.0 \mathrm{~mm}$, scan range of $2 \theta=5$ to 60 degree. The crystalline size of the PbS QDs was determined at cubic $\mathrm{PbS}(220)$ peak $(2 \theta=42$ degree) based on Scherrer equation by using analysis software (PDXL ver.2.6 1.2). 
The weight concentrations of $\mathrm{Pb}$ in the $\mathrm{PbS} \mathrm{QD}$ solids were determined by ICP analysis of clear solutions dissolved in $\mathrm{HNO}_{3} / \mathrm{H}_{2} \mathrm{O}_{2}$ mixture ${ }^{37}$. The weight concentrations of oleic acid in the PbS QD solids were measured by ${ }^{1} \mathrm{H}$ NMR spectra with dibromomethane as an internal standard in deuterated toluene ( 99 atom\%D, tetramethylsilane (TMS) 0.03 volume $\%$ ) or deuterated DMF $(99.5$ atom $\% \mathrm{D})^{38}$. The ${ }^{1} \mathrm{H}$ NMR data were obtained on a NMR spectrometer (Agilent, VNMR400), operating at ${ }^{1} \mathrm{H}$ frequency of $400 \mathrm{MHz}$, delay time of $60 \mathrm{~s}$, integration of 32 times. The atomic ratios of $\mathrm{Pb} / \mathrm{S} / \mathrm{I} / \mathrm{N}$ in the $\mathrm{PbS} \mathrm{QD}$ solids were determined from the area ratios of $\mathrm{Pb} 4 \mathrm{f}, \mathrm{S} 2 \mathrm{p}, \mathrm{I} 3 \mathrm{~d}$, and $\mathrm{N} 1 \mathrm{~s}$ in XPS data ${ }^{23,39}$. The XPS spectra were measured on a XPS spectrometer (Ulvac-phi, PHI Quantera SXM) using monochromatic AlK $\alpha$ radiation $(25 \mathrm{~W}, 15 \mathrm{kV})$ under the conditions of beam size of $100 \mu \mathrm{m}$, area of $1 \mathrm{~mm}^{2}$, pulse energy of $112 \mathrm{eV}$, step of $0.2 \mathrm{eV}$, detection angle of 45 degree, binding energy correction $\mathrm{C} 1 \mathrm{~s}(284.8 \mathrm{eV})$.

Scanning electron microscopy (SEM) images of the photo-absorption layer surface were obtained on a field emission-scanning electron microscope (FE-SEM, Hitachi, S-4800), operating at $10 \mathrm{kV}$. The fraction of surface coverage of the perovskite on the $\mathrm{mTiO}_{2}$ layer was calculated from the SEM images (magnification of 10,000 ) by using an image analysis software (WinROOF, Mitani Corp.). The structure of the PbS QDs and the perovskite in the photo-absorption layer with the $\mathrm{PbS}$ QDs of 14 volume $\%$ was analyzed at $153 \mathrm{~K}$ using a cryo-system for less perturbation of electron beams. The cross-sectional film samples with the thickness of $150 \mathrm{~nm}$ were prepared at $153 \mathrm{~K}$ by slicing on a micro-sampling focused ionbeam apparatus (FIB, Hitachi, NB-5000) after depositions of carbon (C) and tungsten $(\mathrm{W})$ as protective layers. The cryo-SEM images (secondary electron) were obtained on a scanning and transmission electron microscope (STEM, Hitachi, HD-2300), operating at $200 \mathrm{kV}$. High-resolution transmission electron microscope (HRTEM) characterization was performed at $153 \mathrm{~K}$ using high-resolution transmission electron microscope (Hitachi, H-9500), operating at $300 \mathrm{kV}$. Under the STEM and HRTEM observations, we found that some particles of the PbS QDs were aggregated to form the larger particles with the size of more than $10 \mathrm{~nm}$ by the electron beams. Thus, we could not exactly determine the particle size and the particle density of the PbS QDs in the photo-absorption layer by STEM and HRTEM. Although the lattice constants of $\mathrm{PbS}^{30}$ and $\mathrm{MAPbBr}_{3}{ }^{29}$ are well matched, we could not get direct evidence of the match of the lattice orientation ${ }^{25}$ between $\mathrm{PbS}$ QDs and $\mathrm{MAPbBr}_{3}$ matrix.

Optical properties. Transmission absorption spectra of dispersions of the PbS QDs and of the photo-absorption layers on glass substrates were measured at room temperature on an ultraviolet (UV)-visible (Vis)-near infrared (NIR) spectrometer (Shimadzu, Solid Spec-3700) under the conditions of a detective unit of integrating sphere, scanning speed of normal, sampling pitch of $1 \mathrm{~nm}$, slit width of 20 , measurement range of 300 to $1600 \mathrm{~nm}$. Background measurements were performed using toluene or DMF solvent in a quartz cell ( $10 \mathrm{~mm}$ path length) for the PbS QD dispersions and the glass substrate for the photo-absorption layers on glass substrates, respectively. In the transmission absorption spectra of the photo-absorption layers, no absorption peak at around $1000 \mathrm{~nm}$ assigned to the PbS QDs was observed, so it was not possible to estimate the $E_{\mathrm{BG}}$ of the PbS QDs in the photoabsorption layers.

NIR PL spectra ranging from 1000 to $1600 \mathrm{~nm}$ of the photo-absorption layers on glass substrates were measured at room temperature on a photoluminescence spectrometer using laser diode light source $(15 \mathrm{~mW})$ at excitation wavelength of $532 \mathrm{~nm}$ (excitation of the perovskite) and $785 \mathrm{~nm}$ (excitation of the PbS QDs) Excitation density dependence of the NIR PL spectra was performed at room temperature under the conditions of excitation wavelength of $532 \mathrm{~nm}$, excitation power from 1 to $78 \mathrm{~mW}$, and laser spot diameter of $90 \mu \mathrm{m}$. The integrated PL emission intensity and PL emission peak wavelengths were determined by Gaussian-fitting. Visible light PL spectra ranging from 500 to $850 \mathrm{~nm}$ were obtained at room temperature on a photoluminescence spectrometer (Horiba, Fluorolog) under the conditions of excitation wavelength of $480 \mathrm{~nm}$, slit width of excitation light of $1 \mathrm{~nm}$, slit width of emission light of $5 \mathrm{~nm}$, dark-offset on. Timeresolved PL experiments were performed at room temperature on a photoluminescence lifetime measurement apparatus (Hamamatsu Photonics, Quantaurus-Tau C11369). Emission decay curves from 0 to $100 \mathrm{~ns}$ of the perovskite in the photo-absorption layers on glass substrates were measured at 544 $\mathrm{nm}$ with a time resolution of $100 \mathrm{ps}$ (excitation wavelength $470 \mathrm{~nm}$ ). The emission lifetimes were calculated on the basis of two-exponential-decay fitting.

Solar cell properties. The photocurrent density-voltage $(\mathrm{J}-\mathrm{V})$ curves of the cells with the photo-absorption layers were recorded at room temperature in air using a solar simulator (Peccell Technologies, PEC-L01) under AM $1.5 \mathrm{G}$ condition $\left(100 \mathrm{~mW} \mathrm{~cm}{ }^{-2}\right)$. Cell active area of $0.036 \mathrm{~cm}^{2}$ was defined by a black metal mask. Scan rate, step voltage, search delay, hold time, and scan range were fixed at $0.1 \mathrm{~V} \mathrm{~s}^{-1}, 0.01 \mathrm{~V}, 0.05 \mathrm{~s}, 0.05 \mathrm{~s}$, and $-0.1 \mathrm{~V}$ to $1.1 \mathrm{~V}$, respectively. The light intensity was corrected with a calibrated Si reference cell (Bunkoukeiki, BS-520).

The external quantum efficiency (EQE) spectra of the cells with the photoabsorption layers were measured at room temperature in air on a spectral response measurement system (Bunkoukeiki, CEP-2000MLR, direct current (DC) method) with a metal mask to give an active area of $0.036 \mathrm{~cm}^{2}$. The power of the incident monochromatic light was kept under $2.5 \mathrm{~mW} \mathrm{~cm}^{-2}$, which was calibrated with a Si reference cell (Bunkoukeiki, BS-520BK).
The difference in $\mathrm{EQE}(\triangle \mathrm{EQE})$ spectra between with and without IR bias light illumination were measured at room temperature in air using two-step photon absorption (TSPA) photocurrent spectroscopy with IR bias light ${ }^{4,5,7-11}$. The wavelength of the IR bias light was more than $1319 \mathrm{~nm}$ or $1500 \mathrm{~nm}$. The IR bias light can pump electrons only from the intermediate-band (IB) to conduction band (CB) of the perovskite neither from the valence band (VB) to IB nor from the VB to $\mathrm{CB}$. The $\triangle \mathrm{EQE}$ spectra were obtained on a spectral response measurement setup (alternating current (AC) method, active area $0.036 \mathrm{~cm}^{2}$ ) by using a lock-in amplifier synchronized with an optical chopper set at $5 \mathrm{~Hz}$. A halogen lamp (100 $\mathrm{W})$ was used as a monochromatic light source with the photon density ranging from $1 \times 10^{13}$ photon $\mathrm{cm}^{-2} \mathrm{~s}^{-1}$ at $500 \mathrm{~nm}$ to $1 \times 10^{16}$ photon $\mathrm{cm}^{-2} \mathrm{~s}^{-1}$ at 1100 $\mathrm{nm}$, which was enough low to ignore filling of the IB. The IR bias light from the other tungsten lamp passed through the optical chopper and an appropriate set of filters that allowed only the IR region of more than $1319 \mathrm{~nm}$ or more than $1500 \mathrm{~nm}$ to be transmitted. The power of the IR bias light was $56 \mathrm{~mW} \mathrm{~cm}^{-2}$ (more than $1319 \mathrm{~nm}$ ) or $50 \mathrm{~mW} \mathrm{~cm}^{-2}$ (more than $1500 \mathrm{~nm}$ ). Difference spectra in the $\triangle \mathrm{EQE}$ were calculated based on subtraction the $\triangle \mathrm{EQE}$ using the long-pass filter of $1500 \mathrm{~nm}$ $\left(\triangle \mathrm{EQE}_{1500}\right)$ from the $\triangle \mathrm{EQE}$ using the long-pass filter of $1319 \mathrm{~nm}\left(\triangle \mathrm{EQE}_{1319}\right)$.

\section{Data availability}

All relevant data are available from the corresponding author upon reasonable request.

Received: 15 June 2018 Accepted: 16 November 2018 Published online: 10 January 2019

\section{References}

1. Shockley, W. \& Queisser, H. J. Detailed balance limit of efficiency of p-n junction solar cells. J. Appl. Phys. 32, 510-519 (1961).

2. Luque, A. \& Martí, A. Increasing the efficiency of ideal solar cells by photon induced transitions at intermediate levels. Phys. Rev. Lett. 78, 5014-5017 (1997).

3. Luque, A., Martí, A. \& Stanley, C. Understanding intermediate-band solar cells. Nat. Photon. 6, 146-152 (2012).

4. Okada, Y. et al. Intermediate band solar cells: recent progress and future directions. Appl. Phys. Rev. 2, 021302-1-48 (2015).

5. Martí, A. et al. Production of photocurrent due to intermediate-to-conduction band transitions: a demonstration of a key operating principle of the intermediate-band solar cell. Phys. Rev. Lett. 97, 247701-1-4 (2006).

6. Hubbard, S. M. et al. Effect of strain compensation on quantum dot enhanced GaAs solar cells. Appl. Phys. Lett. 92, 123512-1-3 (2008).

7. Okada, Y. et al. Increase in photocurrent by optical transitions via intermediate quantum states in direct-doped InAs/GaNAs straincompensated quantum dot solar cell. J. Appl. Phys. 109, 024301-1-5 (2011).

8. Sogabe, T. et al. Intermediate-band dynamics of quantum dot solar cell in concentrator photovoltaic modules. Sci. Rep. 4, 4792-1-7 (2014).

9. López, E. et al. Demonstration of the operation principles of intermediate band solar cells at room temperature. Sol. Energy Mater. Sol. Cells 149, 15-18 (2016).

10. Shoji, Y., Tamaki, R. \& Okada, Y. Multi-stacked GaSb/GaAs type-II quantum nanostructures for application to intermediate band solar cells. AIP Adv. 7, 065305-1-7 (2017).

11. Asahi, S., Teranishi, H., Kusaki, K., Kaizu, T. \& Kita, T. Two-step photon upconversion solar cells. Nat. Commun. 8, 14962-1-9 (2017).

12. Vörös, M., Galli, G. \& Zimanyi, G. T. Colloidal nanoparticles for intermediate band solar cells. ACS Nano 9, 6882-6890 (2015).

13. Kojima, A., Teshima, K., Shirai, Y. \& Miyasaka, T. Organometal halide perovskites as visible-light sensitizers for photovoltaic cells. J. Am. Chem. Soc. 131, 6050-6051 (2009).

14. Ryu, S. et al. Voltage output of efficient perovskite solar cells with high opencircuit voltage and fill factor. Energy Environ. Sci. 7, 2614-2618 (2014).

15. Yang, W. S. et al. High-performance photovoltaic perovskite layers fabricated through intramolecular exchange. Science 348, 1234-1237 (2015).

16. Saliba, M. et al. Incorporation of rubidium cations into perovskite solar cells improves photovoltaic performance. Science 354, 206-209 (2016).

17. Tan, H. et al. Efficient and stable solution-processed planar perovskite solar cells via contact passivation. Science 355, 722-726 (2017).

18. Yang, W. S. et al. Iodide management in formamidinium-lead-halide-based perovskite layers for efficient solar cells. Science 356, 1376-1379 (2017).

19. Hou, Y. et al. A generic interface to reduce the efficiency-stability-cost gap of perovskite solar cells. Science 358, 1192-1197 (2017).

20. Nozik, A. J. et al. Semiconductor quantum dots and quantum dot arrays and applications of multiple exciton generation to third-generation photovoltaic solar cells. Chem. Rev. 110, 6873-6890 (2010). 
21. Chuang, C.-H. M., Brown, P. R., Bulović, V. \& Bawendi, M. G. Improved performance and stability in quantum dot solar cells through band alignment engineering. Nat. Mater. 13, 796-801 (2014).

22. Carey, G. H. et al. Colloidal quantum dot solar cells. Chem. Rev. 115 , 12732-12763 (2015).

23. Lan, X. et al. $10.6 \%$ certified colloidal quantum dot solar cells via solventpolarity-engineered halide passivation. Nano. Lett. 16, 4630-4634 (2016).

24. Choi, J. et al. Chloride passivation of $\mathrm{ZnO}$ electrodes improves charge extraction in colloidal quantum dot photovoltaics. Adv. Mater. 29, 1702350-15 (2017).

25. Ning, Z. et al. Quantum-dot-in-perovskite solids. Nature 523, 324-328 (2015).

26. Gong, X. et al. Highly efficient quantum dot near-infrared light-emitting diodes. Nat. Photon. 10, 253-257 (2016).

27. García de Arquer, F. P. et al. Field-emission from quantum-dot-in-perovskite solids. Nat. Commun. 8, 14757-1-8 (2017).

28. Sameshima, K., Sano, T. \& Yamaguchi, K. Self-formation of ultrahigh-density $\left(10^{12} \mathrm{~cm}^{-2}\right)$ InAs quantum dots on InAsSb/GaAs(001) and their photoluminescence properties. Appl. Phys. Express 9, 075501-1-4 (2016).

29. Poglitsch, A. \& Weber, D. Dynamic disorder in methylammoniumtrihalogenoplumbates (II) observed by millimeter-wave spectroscopy. J. Chem. Phys. 87, 6373-6378 (1987).

30. Wyckoff, R. W. G. Crystal structure, 2nd edn. (Interscience Publishers, New York, 1963).

31. Sugaya, T., Amano, T., Mori, M. \& Niki, S. Miniband formation in InGaAs quantum dot superlattice. Appl. Phys. Lett. 97, 043112-1-3 (2010).

32. Shi, D. et al. Low trap-state density and long carrier diffusion in organolead trihalide perovskite single crystals. Science 347, 519-522 (2015).

33. Wei, G. \& Forrest, S. R. Intermediate-band solar cells employing quantum dots embedded in an energy fence barrier. Nano. Lett. 7, 218-222 (2007).

34. Yoshida, M., Ekins-Daukes, N. J., Farrell, D. J. \& Phillips, C. C. Photon ratchet intermediate band solar cells. Appl. Phys. Lett. 100, 263902-1-4 (2012).

35. Hines, M. A. \& Scholes, G. D. Colloidal PbS nanocrystals with size-tunable near-infrared emission: observation of post-synthesis self-narrowing of the particle size distribution. Adv. Mater. 15, 1844-1849 (2003).

36. Hanusch, F. C. et al. Efficient planar heterojunction perovskite solar cells based on formamidinium lead bromide. J. Phys. Chem. Lett. 5, 2791-2795 (2014).

37. Cademartiri, L. et al. Size-dependent extinction coefficients of $\mathrm{PbS}$ quantum dots. J. Am. Chem. Soc. 128, 10337-10346 (2006).

38. Moreels, I. et al. Size-tunable, bright, and stable PbS quantum dots: a surface chemistry study. ACS Nano 5, 2004-2012 (2011).

39. Zhang, J., Gao, J., Miller, E. M., Luther, J. M. \& Beard, M. C. Diffusioncontrolled synthesis of $\mathrm{PbS}$ and $\mathrm{PbSe}$ quantum dots with in situ halide passivation for quantum dot solar cells. ACS Nano 8, 614-622 (2014).

\section{Acknowledgements}

We acknowledge Dr. A. Wakamiya at Kyoto University for his advice in the fabrication of solar cells. A part of this work was conducted at Kyushu University, supported by Nanotechnology Platform Program (Molecule and Material Synthesis) of the Ministry of Education, Culture, Sports, Science and Technology (MEXT), Japan.

\section{Author contributions}

H.H., T.S., H.S., and T.Y. conceived the design. H.H., R.T., T.S., A.O., and Y.Og. carried out the experiments and analyzed the results. H.H. and R.T. co-wrote the manuscript with input from all authors. S.H., Y.Ok., and T.Y. supervised the project.

\section{Additional information}

Supplementary Information accompanies this paper at https://doi.org/10.1038/s41467 018-07655-3.

Competing interests: The authors declare no competing interests.

Reprints and permission information is available online at http://npg.nature.com/ reprintsandpermissions/

Publisher's note: Springer Nature remains neutral with regard to jurisdictional claims in published maps and institutional affiliations.

(c) (i) Open Access This article is licensed under a Creative Commons Attribution 4.0 International License, which permits use, sharing, adaptation, distribution and reproduction in any medium or format, as long as you give appropriate credit to the original author(s) and the source, provide a link to the Creative Commons license, and indicate if changes were made. The images or other third party material in this article are included in the article's Creative Commons license, unless indicated otherwise in a credit line to the material. If material is not included in the article's Creative Commons license and your intended use is not permitted by statutory regulation or exceeds the permitted use, you will need to obtain permission directly from the copyright holder. To view a copy of this license, visit http://creativecommons.org/ licenses/by/4.0/.

(C) The Author(s) 2019 